Marquette University

e-Publications@Marquette

Biological Sciences Faculty Research and

Publications

Biological Sciences, Department of

$7-2002$

\title{
Herbivore and Pathogen Damage on Grassland and Woodland Plants: A Test of The Herbivore Uncertainty Principle
}

Stefan A. Schnitzer

Marquette University, stefan.schnitzer@marquette.edu

Peter B. Reich

University of Minnesota

Belle Bergner

University of Pennsylvania

Walter P. Carson

University of Pittsburgh

Follow this and additional works at: https://epublications.marquette.edu/bio_fac

Part of the Biology Commons

\section{Recommended Citation}

Schnitzer, Stefan A.; Reich, Peter B.; Bergner, Belle; and Carson, Walter P., "Herbivore and Pathogen Damage on Grassland and Woodland Plants: A Test of The Herbivore Uncertainty Principle" (2002).

Biological Sciences Faculty Research and Publications. 723.

https://epublications.marquette.edu/bio_fac/723 
Marquette University

e-Publications@Marquette

\title{
Biology Faculty Research and Publications/College of Arts and Sciences
}

This paper is NOT THE PUBLISHED VERSION; but the author's final, peer-reviewed manuscript. The published version may be accessed by following the link in the citation below.

Ecology Letters, Vol. 5, No. 4 (July 2002) : 531-539. DOl. This article is (C) Wiley and permission has been granted for this version to appear in e-Publications@Marquette. Wiley does not grant permission for this article to be further copied/distributed or hosted elsewhere without the express permission from Wiley.

\section{Herbivore and pathogen damage on grassland and woodland plants: a test of the herbivore uncertainty principle}

\author{
Stefan A. Schnitzer \\ Department of Forest Resources, University of Minnesota, St. Paul, MN \\ Peter Reich \\ Department of Forest Resources, University of Minnesota, St. Paul, MN \\ Belle Bergner \\ Department of Biology, University of Pennsylvania, Philadelphia, PA \\ Walter P. Carson \\ Department of Biological Sciences, University of Pittsburgh, Pittsburgh, PA
}

\begin{abstract}
Researchers can alter the behaviour and ecology of their study organisms by conducting such seemingly benign activities as non-destructive measurements and observations. In plant communities, researcher visitation and
\end{abstract}


measurement of plants may increase herbivore damage in some plant species while decreasing it in others. Simply measuring plants could change their competitive ability by altering the amount of herbivore damage that they suffer. Currently, however, there is only limited empirical evidence to support this 'herbivore uncertainty principle' (HUP). We tested the HUP by quantifying the amount of herbivore and pathogen damage in 13 plant species (> 1400 individuals) at four different visitation intensities at Cedar Creek Natural History Area, Minnesota, USA. Altogether, we found very little evidence to support the HUP at any intensity of visitation. Researcher visitation did not alter overall plant herbivore damage or survival and we did not detect a significant visitation effect in any of the 13 species. Pathogen damage also did not significantly vary among visitation treatments, although there was some evidence that high visitation caused slightly higher pathogen damage. Based on our results, we question whether this phenomenon should be considered a 'principle' of plant ecology.

\section{INTRODUCTION}

In 1927, Werner Heisenberg introduced the Uncertainty Principle, demonstrating that the act of measuring the physical properties of a particle would alter the behaviour of that particle (9). Heisenberg posited that the more precisely one measures one property of a particle, for example the particle's position, the greater effect there is on another property, such as the particle's momentum. Although Heisenberg's Uncertainty Principle pertains specifically to quantum physics, its utility has transcended the field of physics and become of importance to experimentalists in many scientific disciplines. In avian ecology, for example, researcher visitation of bird nests can alter the rate of egg predation in some species $(\underline{27} ; \underline{13} ; \underline{14})$. Additionally, the use of coloured ankle bands to track and identify individuals can inadvertently increase aggressive behaviour or alter mate choice $(\underline{\mathbf{3}} ; \underline{\mathbf{1 7}})$. Consequently, some general aspects of Heisenberg's Uncertainty Principle appear to have important ramifications in ecology.

Recently, 4) extended Heisenberg's Uncertainty Principle to plant communities, suggesting that the amount of insect herbivory on plants is altered by researcher visitation and measurement, a phenomenon that they coined the herbivore uncertainty principle (HUP). They found that after eight weekly mock morphological measurements of leaves and stems, herbivore damage in two of six herbaceous plant species was substantially different from that of control plants, which were visited only once. These findings were particularly important because there was not a proportional, unidirectional response to researcher visitation and measurement; rather, one species had higher herbivore damage, whereas another species had lower herbivore damage. This type of differential, species-specific response to researcher visitation could have huge implications in plant ecology, resulting in incorrect conclusions about the nature of plant-plant and plant-animal interactions. Specifically, if herbivore damage is altered because of researcher visitation, and even a modest change in herbivore damage can reverse the competitive order among species $(\underline{\mathbf{1 2}} ; \underline{\mathbf{1 5}}, \underline{\mathbf{1 6}})$, then the simple act of visiting and measuring plants can cause a shift in the competitive hierarchy of plants and thus fundamentally alter plant community composition. Furthermore, previous plant population- and community-level studies could have confused the response of plants to a specific manipulation with a HUP visitation effect. Consequently, if the HUP is replicable and generalizable, then plant ecologists will have to re-examine current methodologies for studying plant interactions and question the validity of many previous plant population- and community-level studies. $\underline{\text { 4) }}$ warned that further research is urgently needed and that 'In the mean time, researchers must, at the very least, explicitly determine if their own presence affects the function of their study system'.

Although the idea behind the HUP is intriguing, to date there is not sufficient evidence to deem this phenomenon an 'ecological principle'. Specifically, the HUP is based on one study that examined six plant species, only two of which had a significant change in mean leaf damage to visitation and measurement (4). Furthermore, all six of the species shared a similar life-history strategy, being relatively fast-growing, shadeintolerant, early successional herbaceous plants. Finally, the study was not replicated at the site level, being 
based on a single field in Pennsylvania, USA. Nevertheless, the huge potential implications of the HUP warranted a more comprehensive test of this phenomenon at an alternate site, using a replicated experimental design that also quantified the sensitivity of plants to different frequencies of experimental visitation.

We designed an experiment to test whether: (1) the HUP is a replicable and generalizable phenomenon; (2) pathogen damage, in addition to herbivore damage, is altered by researcher visitation; and (3) an increase in the frequency of researcher visitation alters the magnitude of herbivore and pathogen damage. We expanded the previous test of the HUP in four explicit ways, several of which were specifically called for by 4 ). First, we tested the HUP in six separate fields at Cedar Creek Natural History Area in central Minnesota, USA, to determine whether it was generalizable to the old field plant community of this region. Secondly, in addition to quantifying foliar herbivore damage, we also quantified the amount of foliar pathogen damage. Foliar pathogen damage can substantially reduce plant health by reducing growth and altering patterns of root to shoot allocation (18). Because pathogens can spread among plants via vectors such as small mammals and invertebrates $(\underline{\mathbf{8}} ; \underline{\mathbf{1 0}} ; \underline{\mathbf{1}})$, it is also likely that pathogens can spread from plant to plant via researchers' hands, clothing or their measurement instruments. Thirdly, we included both herbaceous and woody species to determine if the HUP might be a general phenomenon in vascular plants. Finally, we included a gradient of frequencies of researcher visitation in an attempt to determine the sensitivity of plants to researcher visitation. Recognizing the point at which visitation alters the rates of herbivore and pathogen damage may guide researchers in developing experimental protocols that would minimize the unintended effects of researcher visitation.

\section{METHODS}

\section{Study area}

We tested the herbivore uncertainty principle in six old fields at Cedar Creek Natural History Area in central Minnesota, USA. Cedar Creek is a $22-\mathrm{km}^{2}$ mosaic of forests, wetlands, abandoned agricultural fields and native oak savannas, located within the transition zones of western prairie, eastern deciduous forest and northern conifer forest. The soils of Cedar Creek tend to be coarse-textured and sandy, which makes them somewhat nutrient poor (24; 11). The flora of Cedar Creek, however, is relatively species-rich, with over 750 vascular plant species (20). The six replicate fields that we selected were spread throughout Cedar Creek, with none of the fields closer than $1 \mathrm{~km}$ to another. All of the fields had been fallow for 25-45 years and had a sufficiently high abundance of the target species, particularly perennial forbs and woody plants, to allow us to adequately replicate each treatment.

\section{Treatments}

Our visitation and measurement treatment was similar to that of $\underline{4}$ ), consisting of mock stem diameter and height measurements of each plant, a process by which we gently straightened each plant perpendicular to the ground, simulating stem diameter and height measurements. We were careful not to physically damage the plants; thus, we never forced stems into a vertical position if a plant did not allow for this type of position. We also arbitrarily touched certain leaves of each plant, simulating additional morphometric leaf measurements. We used four visitation frequencies, consisting of: (1) high visitation (once per week); (2) medium visitation (once every 2 weeks); (3) low visitation (once every 4 weeks); and (4) a control treatment in which we visited the plants only at the end of the study, when we quantified herbivore and pathogen damage. By not visiting our control treatment until the end of the study we had the greatest possible contrast with the high visitation treatment. Indeed, 4) suggested that they would have seen an even greater influence of visitation if they had used a no visitation control treatment. Overall, our experimental design should have allowed us to quantify the sensitivity of plants over a relatively large gradient of visitation frequency and measurement. 


\section{Plant community}

We selected 13 target plant species for this study, nine of which were herbaceous and four woody, comprising 1437 individuals (Table 1). Because species composition was highly variable among the sites, it was not possible to locate each species at every site; rather, we selected seven to nine target species per site, including at least two woody species per site. Ten of the 13 species were replicated at more than one site, while three species (Acer rubrum, Solidago missouriensis and Solidago ridgida) were found at only one site (Table 1). For each of the three visitation treatments within each field, we selected up to 10 individuals of each target species as we encountered them along a meandering path (hereafter called transect) through each field (21). We marked the plants by loosely tying coloured flagging tape near the base of their stems. Each plant was usually separated by at least $1 \mathrm{~m}$ from any other target plant (methods follow those of $\underline{4}$ ) and the treatments were separated by at least $5 \mathrm{~m}$. After the plants were marked, we randomly assigned a visitation treatment for each transect. For the control treatment, we randomly selected 10 additional individuals of each target species within the same sampling area of the field used to sample the other individuals. We were careful to locate the control transects in areas that had not been visited throughout the summer and we constrained all four treatments to the same general area of the field to ensure that each transect was an accurate representation of the targeted species community for each field.

\begin{tabular}{llll}
\hline & Life-history & $\begin{array}{l}\text { No. of } \\
\text { sites }\end{array}$ & $\begin{array}{l}\text { No. of } \\
\text { individuals }\end{array}$ \\
\hline Anecies & Perennial forb & 4 & 114 \\
Fragaria vinginiana & Perennial forb & 5 & 173 \\
Monarda fistulosa & Perennial forb & 3 & 88 \\
Potentilla recta & Perennial forb & 5 & 174 \\
Rubus allegheniensis & Perennial forb & 6 & 212 \\
Solidago gigantea & Perennial forb & 4 & 156 \\
Solidago missouriensis & Perennial forb & 1 & 37 \\
Solidago rigida & Perennial forb & 1 & 33 \\
Latbyrus venosus & Perennial legume & 2 & 63 \\
Corylus americana & Shrub & 2 & 66 \\
Acer rubrum & Tree & 1 & 27 \\
Populus tremuloides & Tree & 4 & 121 \\
Quercus ellipsoidalis & Tree & 5 & 172 \\
\hline
\end{tabular}

Table 1. The species identity, life-history strategy, number of replicated sites and number of individuals for each of the 13 plant species included in this study. All woody species were less than $2 \mathrm{~m}$ tall. In total, there were 1437 individuals in this study

\begin{tabular}{|l|l|l|l|}
\hline Species & Life-history & $\begin{array}{l}\text { No. of } \\
\text { sites }\end{array}$ & $\begin{array}{l}\text { No. of } \\
\text { individu }\end{array}$ \\
\hline Anemone cylindrica & Perennial forb & 4 & 114 \\
\hline Fragaria virginiana & Perennial forb & 5 & 173 \\
\hline Monarda fistulosa & Perennial forb & 3 & 88 \\
\hline Potentilla recta & Perennial forb & 5 & 174 \\
\hline Rubus allegheniensis & Perennial forb & 6 & 212 \\
\hline Solidago gigantea & Perennial forb & 4 & 156 \\
\hline Solidago missouriensis & Perennial forb & 1 & 37 \\
\hline Solidago rigida & Perennial forb & 1 & 33 \\
\hline Lathyrus venosus & Perennial legume & 2 & 63 \\
\hline Corylus americana & Shrub & 2 & 66 \\
\hline Acer rubrum & Tree & 1 & 27 \\
\hline
\end{tabular}




\begin{tabular}{|l|l|l|l|}
\hline Populus tremuloides & Tree & 4 & 121 \\
\hline Quercus ellipsoidalis & Tree & 5 & 172 \\
\hline
\end{tabular}

\section{Data collection}

We ran the study for 10 weeks, beginning in late May 2001, and quantified survivorship and foliar herbivore and pathogen damage for each species at the end of the study, in early August, when damage was near its peak. We determined foliar herbivore and pathogen damage by comparing the leaves of all of the plants in the experiment with species-specific leaf damage templates, which ranged from 1 to $5 \%$ damage at intervals of $1 \%$, and 5 to $100 \%$ damage at intervals of $5 \%$ ( 25 damage categories in total; methods follow those of $\underline{\mathbf{5}}, \underline{\mathbf{6}}$ ). For each individual, we estimated whole-plant damage by averaging the percentage damage for each leaf, taking individual leaf size into consideration. It was not always possible to distinguish among the different pathogen species and thus we considered all suspicious lesions on the leaves to be damage from pathogens. Some of the lesions, however, may not have been pathogenic, and thus we may have overestimated the amount of actual pathogen damage.

\section{Statistical analyses}

We tested whether researcher visitation and measurement altered the percentage of herbivore and pathogen damage in plant species using several statistical tests. To determine whether researcher visitation altered the amount of herbivore and pathogen damage, we used a three-way, type III sum of squares ANOVA, with visitation frequency, species identity and site as independent factors (SAS Institute 2002). We classified visitation frequency as a fixed effect, but both species identity and site as random effects. To directly compare our two most extreme visitation treatments and to make our study more comparable with the two-treatment design (weekly and once) used by 4 ), we ran an additional three-way ANOVA for both herbivore and pathogen damage using only the control and the high visitation treatments. The results for this two-

treatment ANOVA were similar to the four-treatment ANOVA described above and so we do not report these results. We tested whether woody and herbaceous species (broadly defined as different life-history strategies) responded differently to researcher visitation with a three-way ANOVA, lumping the species as either herbaceous ( $n=9$ ) or woody $(n=4)$. We did not use Bonferroni corrections for these analyses, which would have been an appropriate but more conservative approach (23). For all ANOVAs, we used the mean percentage herbivore and pathogen damage estimates for each species (or life-history strategy) per transect and arcsin

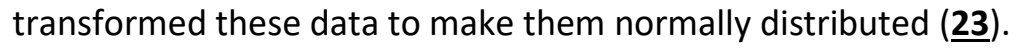

We used a two-tailed Fisher's exact test to determine whether researcher visitation consistently increased or decreased the mean herbivore and pathogen damage among the species. The Fisher's exact test calculates the probability of obtaining the frequency of two dichotomous variables compared with a random distribution (23; 26). For this test, we scored the herbivore and pathogen damage data as either higher or lower in the high visitation than the control treatment. We then calculated the probability of whether herbivore or pathogen damage was consistently higher or lower in the high visitation than the control treatment among all of the species.

The plant survival analyses were similar to the herbivore and pathogen damage analyses. Specifically, we used a three-way ANOVA with percentage survival as the dependent variable and visitation frequency, site and species identity as the independent variables. However, because there was no significant site effect, we re-ran the ANOVA omitting this variable. In this analysis, we included only the three visitation treatments because we could not collect survival data on the control treatment without altering the treatment. Our one visitation per month treatment, however, was suitable as a low-visitation treatment. 


\section{RESULTS}

\section{Herbivore damage}

Researcher visitation and measurement did not significantly alter foliar herbivore damage in this study (Fig. 1a). Although species differed in the amount of herbivore damage they experienced, there were no significant differences in herbivore damage among the visitation frequencies, the sites, or, more importantly, the visitation frequency by species or by site interactions ( $\left.\begin{array}{ll}\text { Table } 2 & 2\end{array}\right)$. When grouped by life-history strategy, visitation frequency did not alter herbivore damage in either woody or herbaceous species, nor were there visitation frequency by life-history or site interactions (Table 2). The woody species sustained nearly twice the percentage of herbivore damage than did the herbaceous species $(5.5 \pm 0.2$ vs. $2.6 \pm 0.1$, respectively; $P$ $<0.0001$ ), suggesting that species and life-history differences play a much greater role in herbivore damage than researcher visitation.
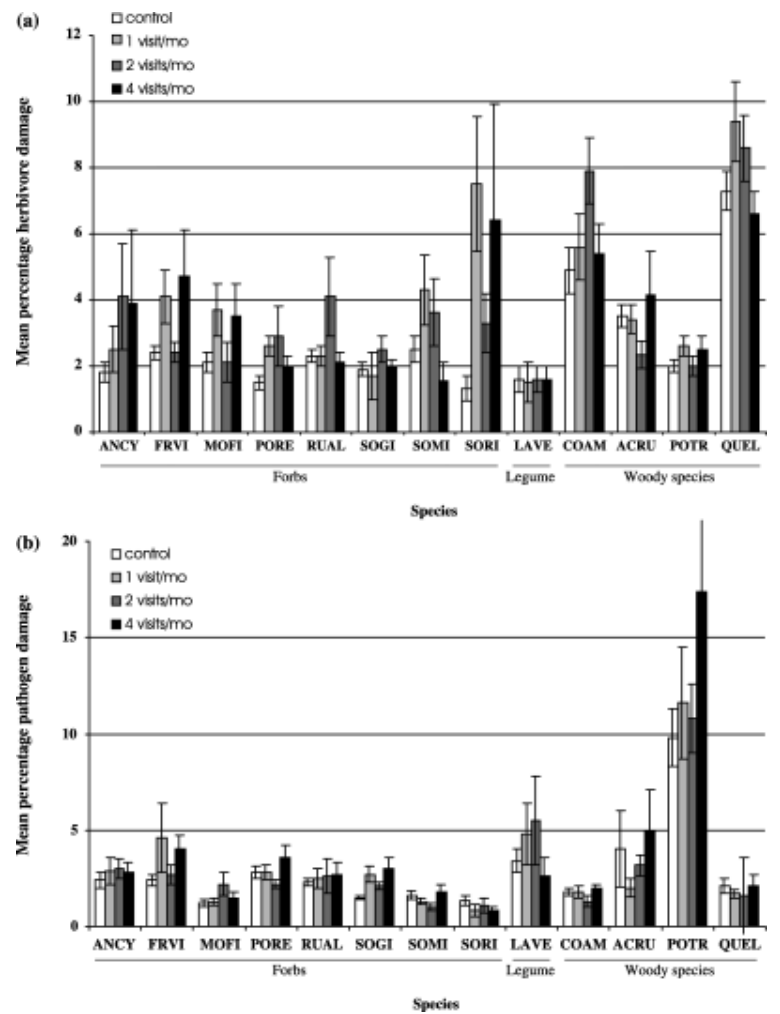

Figure 1 The mean percentage foliar herbivore (a) and pathogen (b) damage for 13 plant species over four visitation frequencies: no visitation (control), low visitation (one visit per month), medium visitation (two visits per month) and high visitation (four visits per month). The amount of herbivore or pathogen damage was not significantly different at any of the visitation frequencies for any of the 13 species (Table 2). Error bars represent standard errors. Here we present non-transformed data; however, we arcsin transformed the data prior to the ANOVAs. The complete species list can be found in Table 1. 


\begin{tabular}{|c|c|c|c|c|c|c|c|c|}
\hline \multirow[b]{2}{*}{ Source } & \multicolumn{4}{|c|}{ Herbivore damage } & \multicolumn{4}{|c|}{ Pathogen damage } \\
\hline & s.s. & d.f. & $F$ & $P$ & s.s. & d.f. & $F$ & $P$ \\
\hline \multicolumn{9}{|l|}{ Al/ species } \\
\hline Visitation freq (Vf) & 0.0001 & 3 & 1.90 & 0.13 & 0.00001 & 3 & 0.08 & 0.97 \\
\hline Species & 0.004 & 12 & 15.32 & $<0.0001$ & 0.004 & 12 & 11.14 & $<0.0001$ \\
\hline Site & 0.00000 & 5 & 0.02 & 0.99 & 0.0005 & 5 & 3.42 & 0.007 \\
\hline Vf $\times$ species & 0.0006 & 36 & 0.83 & 0.73 & 0.0003 & 36 & 0.32 & 0.99 \\
\hline Vf $\times$ site & 0.0003 & 15 & 0.87 & 0.60 & 0.0005 & 15 & 1.13 & 0.34 \\
\hline \multicolumn{9}{|c|}{ Species groups by life-bistory characteristics } \\
\hline Visitation freq (Vf) & 0.00007 & 3 & 0.86 & 0.46 & 0.00007 & 3 & 0.54 & 0.65 \\
\hline Life-history & 0.0018 & 1 & 60.12 & $<0.0001$ & 0.0009 & 1 & 20.91 & $<0.0001$ \\
\hline Site & 0,00000 & 5 & 0.0000 & 1.00 & 0.0007 & 5 & 3.40 & $<0.006$ \\
\hline $\mathrm{Vf} \times$ life-history & 0.00000 & 3 & 0.09 & 0.97 & 0.00005 & 3 & 0.42 & 0.74 \\
\hline $\mathrm{Vf} \times$ site & 0.0002 & 15 & 0.38 & 0.98 & 0.0005 & 15 & 0.71 & 0.77 \\
\hline
\end{tabular}

Table 2. Three-way ANOVA results for the percentage herbivore and pathogen damage for all species (top) and by grouping the species into woody or herbaceous life-history strategies (bottom). In each analysis, the percentage herbivore damage and pathogen damage were the dependent variables, and visitation frequency, species (or species grouped into life-history strategies) and site the independent variables. Statistically significant results are listed in bold type. The percentage herbivore and pathogen damage data were nonnormally distributed, so we arcsin transformed these data prior to the analyses (23)

\begin{tabular}{|l|l|l|l|l|l|l|l|l|l|}
\hline & $\begin{array}{l}\text { Herbivore } \\
\text { damage }\end{array}$ & & & & $\begin{array}{l}\text { Pathogen } \\
\text { damage }\end{array}$ & & & \\
\hline Source & s.s. & d.f. & $F$ & $P$ & s.s. & d.f. & $F$ & $P$ \\
\hline All species & & & & & & & & \\
\hline Visitation freq (Vf) & 0.0001 & 3 & 1.90 & 0.13 & 0.00001 & 3 & 0.08 & 0.97 \\
\hline Species & 0.004 & 12 & 15.32 & $<$ & 0.004 & 12 & 11.14 & $<$ \\
& & & & 0.0001 & & & \\
\hline Site & 0.00000 & 5 & 0.02 & 0.99 & 0.0005 & 5 & 3.42 & 0.000 \\
\hline Vf - species & 0.0006 & 36 & 0.83 & 0.73 & 0.0003 & 36 & 0.32 & 0.99 \\
\hline Vf - site & 0.0003 & 15 & 0.87 & 0.60 & 0.0005 & 15 & 1.13 & 0.34 \\
\hline $\begin{array}{l}\text { Species groups by life-history } \\
\text { characteristics }\end{array}$ & & & & & & & & \\
\hline Visitation freq (Vf) & & & & & & & & \\
\hline Life-history & 0.00007 & 3 & 0.86 & 0.46 & 0.00007 & 3 & 0.54 & 0.65 \\
\hline Site & 0.0018 & 1 & 60.12 & $<$ & 0.0009 & 1 & 20.91 & $<$ \\
\hline Vf - life-history & & & & 0.0001 & & & & 0.0001 \\
\hline Vf - site & 0.00000 & 5 & 0.0000 & 1.00 & 0.0007 & 5 & 3.40 & $<0.006$ \\
\hline
\end{tabular}

\section{Pathogen damage}

Similar to patterns of herbivore damage, researcher visitation did not significantly alter mean pathogen damage in any of the species (Fig. 1b). Specifically, there were no significant differences among the four visitation frequencies, nor were there significant visitation frequency by species or site interactions ( $\underline{\text { Table 2 }}$ ). However, there was a significant tendency for higher pathogen damage in the high visitation treatments compared with the control treatments ( $\underline{P=0.04}$, Fisher's exact test; Fig. $1 \mathbf{b})$. Specifically, 10 of the 13 species had more pathogen damage in the high visitation treatment than in the control, while only two species had less pathogen damage (one species had the same amount). The average absolute difference in pathogen damage between the 
high and control treatments, however, was very low at the end of the growing season (1.2\%) and, with the exception of $P$. tremuloides, none of the species had more than a 1.8\% difference between the high and control treatments. It remains unknown whether this slight increase in pathogen damage could have resulted in a detectable biological effect on the plant. There was no effect of visitation frequency on pathogen damage when we analysed the species grouped according to life-history strategy ( $\left.\begin{array}{ll}\text { Table } 2\end{array}\right)$. As with the amount of herbivore damage, however, pathogen damage was significantly greater in the woody than herbaceous species $(5.1 \pm$ 0.3 vs. $2.6 \pm 0.2$, respectively). Nevertheless, researcher visitation did not cause a significant change in mean pathogen damage in either the woody or herbaceous species.

\section{Plant survival}

Plant survival was high for all species and did not vary among the three visitation frequencies (Fig. 2). Indeed, the mean survival rates among the treatments were remarkably similar. Combined across all species, 93.5\%, 93.3\% and 93.1\% survived throughout the study period in the low, medium and high visitation frequencies, respectively. Mean survival was more than $90 \%$ for all species, except for Rubus allegheniensis, in which survival rate was approximately $75 \%$ (Fig. 2). It is possible that we underestimated survival for $R$. allegheniensis, because it was difficult to distinguish whole plant (genet) mortality from the death of the single tagged stem (ramet mortality). We considered a plant to be dead when it was not obvious that any new stems belonged to the old stem's root stock; thus, we were conservative in our survivorship estimates. Nevertheless, all of the species had very high survival rates and were not significantly affected by researcher visitation and measurement.

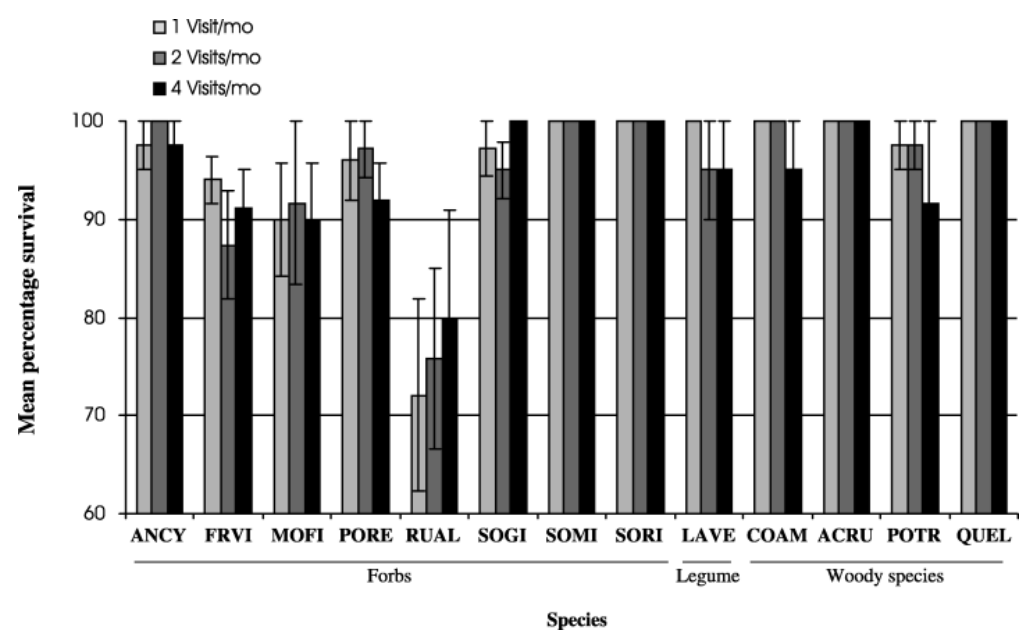

Figure 2 The mean survival rate during the 10-week study period for all 13 species over three visitation frequencies: low visitation (one visit per month), medium visitation (two visits per month) and high visitation (four visits per month). There were no significant differences among the three visitation frequencies for any of the species. A small proportion of the individuals could not be identified at the end of the study because they had died. The number of unidentified individuals, however, was consistent among the treatments; 3.9\% $( \pm 1.3$ $\mathrm{SE}), 3.3 \%( \pm \quad 0.9 \mathrm{SE}$ ) and $2.8 \%( \pm 1.0 \mathrm{SE})$ in the one per month, two per month and four per month treatments, respectively. Error bars represent standard errors.

\section{DISCUSSION}

\section{Testing the herbivore uncertainty principle}

We should have been able to detect the herbivore uncertainty principle if it was present at Cedar Creek, given the power of our experimental design and the large contrast between the high visitation and control treatments. Overall, however, our data did not support the HUP and cast doubt on the generality of this phenomenon. 
Researcher visitation and measurement did not significantly alter mean plant herbivore damage, pathogen damage or survival ([link]Table 2, Figs 1 and 2). These results remained the same for all analyses, including when we grouped the species as woody and herbaceous.

Our results may have differed from those of 4 ) for a variety of reasons. Herbivory was apparently higher in Pennsylvania than at Cedar Creek. Mean herbivore damage ranged from 6 to 25\% in Pennsylvania (4). In contrast, herbivore damage was low at Cedar Creek, averaging less than 3.5\% over all species and treatments (Fig. 1a). Even for the most heavily damaged species, Quercus ellipsoidalis, mean herbivore damage was never more than $10 \%$ in any of the visitation treatments. Direct comparisons of herbivore damage between our results and those of 4), however, are difficult because they lumped herbivore damage into only four discrete categories: $<5 \%, 6-25 \%, 26-75 \%$ and $>76 \%$, whereas we used 25 damage categories. Their method could have introduced a number of problems, the most serious of which is that with only four categories, their precision is low and the smallest possible estimation error would result in a very large error in the herbivore damage data (23). Why we would have been less likely to detect the HUP where damage levels were lower, given our greater level of replication, is also not clear. It is possible that the HUP is detectable only above a certain threshold of herbivore damage, but we cannot substantiate this hypothesis with our data. Regardless, we could not detect the HUP at Cedar Creek, which casts doubt that this phenomenon is a 'principle' in plant ecology. Furthermore, evidence is still lacking whether the HUP plays a strong role in plant communities compared with the strength of plant-insect interactions (e.g. 12; $\underline{\mathbf{6}} ; \underline{2}$ ).

\section{Determining when the herbivore uncertainty principle could be important}

When researcher visitation alters herbivore behaviour

Although our results did not support the HUP, we suggest that the HUP could potentially operate when researcher visitation and measurement alters herbivore behaviour, plant quality, or both. In order to determine whether the HUP will operate in a substantive fashion, researchers will almost certainly require knowledge of the identity and life-history of the dominant or most damaging herbivore species (cf. $\underline{4})$. For example, in an extensive study, 21) surveyed the insects that attack goldenrods (Solidago altissima) through six consecutive growing seasons in 16 old field sites in central New York State. Of the more than 60 insect species that fed on goldenrod, very few species were abundant enough to cause substantial plant damage (see also $\underline{\mathbf{5}}, \underline{\mathbf{6}}$ ). These species included a sedentary leaf chewing beetle (the chrysomelid Trirhabda virgata), an internally feeding leaf miner (the chrysomelid Microrhopala vittata), a sedentary spittle bug (Philaenus spumarius) and a stem galler (Eurosta solidaginis). None of these species, however, are typically disturbed by careful and moderate sampling of goldenrod stems and, for the miners and stem gallers, even intensive and indiscriminate handling would not disturb these well-protected insects (21). Similarly, it seems unlikely that periodic plant measurements would substantially alter the foraging behaviour of highly volant and generalist insects such as grasshoppers; these species can quickly return to favoured hosts. The same is probably true for vertebrate herbivores such as deer and rabbits, which can easily return and forage after researchers have departed. We argue that the herbivores that will be most sensitive to visitation are species that discontinue feeding when disturbed and cannot immediately resume feeding. This cessation in feeding will occur, for example, whenever insects escape from predators by dropping off the disturbed host plant, thereby finding refuge in the litter layer beneath the host plant. In this case, the interval required for the herbivore to resume feeding will determine the magnitude of the decrease in herbivory resulting from researcher visitation and measurement.

Alternatively, herbivore damage may increase if herbivores respond positively to researcher visitation and measurement (4). Although unlikely, it is possible that some insect herbivores could spread passively among host plants by clinging to researchers' hands or clothing. Vertebrate herbivores could follow the trails made by researchers that lead them to tagged and tasty plant species. Both vertebrate and invertebrate herbivores may be attracted or repelled by the scents or salts of researchers left behind on the host plants. 
When visitation alters host plant quality

4) suggested that the primary mechanism underlying the HUP was direct or indirect effects of visitation on the host plant. These effects ranged from 'touch activated plant responses' to the trampling of neighbouring competitors; disturbances that in some way modified host plant susceptibility to herbivores. We consider these above-mentioned mechanisms unlikely given the extent of the disturbance required to elicit a response, even under highly controlled growth chamber conditions (e.g. 25; $\underline{7}$ ), although such responses cannot be ruled out. Furthermore, plants in many systems experience a substantial amount of background mechanical stress from abiotic factors such as wind, which could swamp the effects of researcher visitation.

We suggest that the HUP will skew our interpretation of plant-herbivore interactions only under a narrow set of circumstances. These circumstances may occur when: (1) herbivores either abandon or avoid disturbed plants or become strongly attracted to them; (2) herbivores respond to visitation differently from each other and thus plant species are differentially affected; and (3) the herbivores involved cause significant plant damage, which results in a change in plant competitive ability (photosynthetic ability, biomass allocation, reproduction, etc.). These conditions may occur only rarely and may explain why we found no evidence for the HUP. Nevertheless, any sampling protocol should seek to minimize trampling, minimize host plant handling, and maximize the interval between measurements.

\section{The pathogen uncertainty principle}

Foliar pathogen damage provided an equally meaningful test of the hypothesis that researcher visitation can alter rates of damage in plants. At the onset of this study, we suspected that some pathogens might be spread from plant to plant via researcher's hands or clothing. Consequently, we hypothesized that frequent visitation would increase pathogen damage on our target plants more than it would herbivore damage. Indeed, 10 of the 13 species had greater pathogen damage (albeit only slightly) in the high visitation than the control treatment $(\underline{P}=\mathbf{0 . 0 4}$, Fisher's exact test; Fig. $1 \mathbf{b})$, suggesting that researchers may spread pathogens by frequently visiting and handling plants. This finding, however, was not supported by the ANOVA, which revealed no significant change in pathogen infection with visitation rate for any of the species (Table 2). Furthermore, the mean difference in pathogen damage between the high visitation and control treatments was very small (1.2\%) at the end of the growing season ( $\underline{\text { Fig. }} \mathbf{1 b}$ ). Overall, these results suggest that a high frequency of visitation and measurement may possibly transfer pathogens from plant to plant, but that the amount of resulting pathogen damage may be insignificant.

There are many types of plant pathogens and the likelihood of their transmission by researchers may depend on their mode of dispersal. Fungal pathogens, for example, are typically transmitted passively by spores and many species can be easily transmitted on the hands, clothing or measurement instruments of researchers. Most of the $c .100$ species of bacteria that are pathogenic to plants live on the plant surface and thus can be easily spread by researcher contact (1). There are hundreds of viruses known to infect plants (1), many of which could be easily transmitted from plant to plant on calipers or other measurement instruments. For example, the viruses in the genus Tobamovirus, which includes the tobacco mosaic virus, are readily transmitted by mechanical contact (1). Although we found only a small effect of researcher visitation on the spread of plant pathogens, in systems where pathogens are abundant it may be important to protect against their inadvertent spread. Swabbing instruments after each measurement may reduce the amount of pathogen transmission between plants. This may be particularly important if the plants are conspecifics because many pathogens are species-specific (1).

At Cedar Creek, mean foliar pathogen damage was low; 3.2\% for all individuals at the end of the growing season (Fig. 1b). Actual foliar pathogen damage may have been even lower because we assumed that all lesions were pathogenic. Nevertheless, our estimate of pathogen damage was similar to other published studies. For 
example, in a study at Cedar Creek, 19) reported that mean pathogen damage was approximately $4.3 \%$ in $3 \times$ $3 \mathrm{~m}$ experimental plots that resembled nearby natural grasslands. Plants with somewhat higher levels of pathogen damage (c. $9 \%$ of the leaf area) experienced a significant reduction in total plant biomass and change in root to shoot allocation patterns (18). Furthermore, the actual impact of pathogens on a plant may be much higher than the proportion of leaf area that they physically occupy. For example, $\underline{\mathbf{1 8}}$ ) reported that net photosynthetic capacity decreased by c. $26 \%$ when pathogens infected merely c. $8 \%$ of the leaf area. It is difficult, however, for us to assess the impact on a plant from losing the function of $3.2 \%$ of its leaf area to pathogen damage over the course of the growing season and even more difficult to imagine the biological significance of losing merely $1.2 \%$ more leaf area than a conspecific neighbour that was never visited.

The pathogen uncertainty principle remains a sticky problem. Our results suggest that high visitation and measurement may spread pathogens among plants. However, because none of the species showed a significant increase in the amount of pathogen damage with visitation rate, the transmission of pathogens by researchers may be relatively low and, without much stronger empirical support, does not warrant the label as a 'principle' in plant ecology. Further studies are necessary to test whether the pathogen uncertainty principle is a significant issue and whether it goes beyond the small changes that we observed. Our results on the herbivore uncertainty principle, however, were clear. We found very little evidence to support the herbivore uncertainty principle and therefore we question its importance under common experimental conditions.

\section{ACKNOWLEDGEMENTS}

We thank S. Rutishauser and T. Heinzen for helping with the field work. We are grateful for the suggestions and comments provided by A. Agrawal, B. Bouma, D. Bunker, J. Cahill, G. Gilbert, J. Haarsted, G. Meyer, C. Mitchell, A. Rodewald, M. Tobin, W. Searcy and three anonymous reviewers. Funding was provided, in part, by grants from the National Science Foundation (NSF DEB 961518 and NSF DEB 0080382).

\section{References}

1 Agrios, G.N. (1997). Plant Pathology, 3rd edn. Academic Press, San Diego.

2 Bach, C. (2001). Long-term effects of insect herbivory and sand accretion on plant succession on sand dunes. Ecology, 82, 1401-1416.

3 Burley, N., Krantzberg, G. \& Radman, P. (1982). Influence of colour-banding on the conspecific preferences of zebra finches. Anim Behav, 30, 444- 455.

4 Cahill, J.F., Castelli, J.P. \& Casper, B.B. (2001). The herbivore uncertainty principle: visiting plants can alter herbivory. Ecology, 82, 307- 312.

5 Carson, W.P. \& Root, R.B. (1999). Top-down effects of insect herbivores during early succession: influence on biomass and plant dominance. Oecologia, 121, 260-272.DOI: 10.1007/s004420050928

6 Carson, W.P. \& Root, R.B. (2000). Herbivory and plant species coexistence: community regulation by an outbreaking phytophagous insect. Ecol. Monographs, 70, 73- 99.

7 Cipollini, D.F. (1977). Wind-induced mechanical stimulation increases pest resistance in common bean. Oecologia, 111, 84- 90.DOI: 10.1007/s004420050211

8 El-Hamalawi, Z.A. \& Menge, J.A. (1996). The role of snails and ants in transmitting the avocado stem canker pathogen, Phytophthora citricola. J. Am. Soc. for Hort. Sci., 121, 973- 977.

9 Heisenberg, W. (1927). Uber den anschaulichen inhalt der quantentheoretischen kinematik und mechanik. Zeitscrift Fuer Physik, 43, 172- 198.

10 Hoover, K., Wood, D.L., Storer, A.J., Fox, J.W. \& Bros, W.E. (1996). Transmission of the pitch canker fungus, Fusarium subglutinans F. sp. pini, to Monterey pine, Pinus radiata, by cone-and twig-infesting beetles. Can. Entomologist, 128, 981-994. 
11 Inouye, R.S., Huntly, N.J., Tilman, D., Tester, J.R., Stillwell, M. \& Zinnel, K.C. (1987). Old-field succession on a Minnesota sand plain. Ecology, 68, 12-26.

12 Louda, S.M. (1982). Distribution ecology: variation in plant recruitment in relation to insect seed predation. Ecol. Monographs, 52, 25- 41.

13 Maclvor, L.H., Melvin, S.M. \& Griffin, C.R. (1990). Effects of research activity on piping plover nest predation. J. Wildlife Manage., 54, 443- 447.

14 Mayer-Gross, H., Crick, H.O.P. \& Greenwood, J.J.D. (1997). The effect of observers visiting the nests of passerines: an experimental study. Bird Study, 44, 53- 65.

15 McEvoy, P.B., Cox, C. \& Coombs, E. (1991). Successful biological control of ragwort, Senecio jacabaea, by introduced insects in Oregon. Ecol. Applications, 1, 430-442.

16 McEvoy, P.B., Rudd, N.T., Cox, C. \& Huso, M. (1993). Disturbance, competition, and herbivory effects on ragwort Senecio jacabaea populations. Ecol. Monographs, 63, 55- 75.

17 Metz, K.J. \& Weatherhead, P.J. (1991). Color bands function as secondary sexual traits in male red-winged blackbirds. Behav. Ecol. Sociobiol., 28, 23- 27.

18 Mitchell, C.E. (2001). Global environmental change and foliar fungal plant disease: testing the potential for interactive effects in a grassland ecosystem. PhD thesis, University of Minnesota, St Paul, Minnesota.

19 Mitchell, C.E., Tilman, D. \& Goth, J.V. (2002). Effects of grassland plant species diversity, abundance, and composition on foliar fungal disease. Ecology, 83, 1713- 1726.

20 Moore, J. (1973). A Catalogue of the Flora of Cedar Creek Natural History Area, Anoka and Isanti Counties, Minnesota. Bell Museum of Natural History, Minneapolis, Minnesota.

21 Root, R.B. \& Cappuccino, N. (1992). Patterns in population change and the organization of the insect community associated with goldenrod, Solidago altissima. Ecol. Monographs, 62, 393-420.

22 SAS Institute (2000). JMP Statistics and Graphics Guide, Version 4. SAS Institute Inc, Cary, North Carolina.

23 Sokal, R.R. \& Rohlf, F.J. (1995). Biometry. W.H. Freeman, New York.

24 Tilman, D. (1984). Plant dominance along an experimental nutrient gradient. Ecology, 65, 1445- 1453.

25 Van Emden, V.K., Macklin, R.J. \& Staunton-Lambert, S. (1990). Stroking plants to reduce aphid populations. Entomologist, 109, 184- 188.

26 Weir, B.S. (1996). Genetic Data Analysis II. Sinauer Associates, Sunderland, Massachusetts.

27 Westmoreland, D. \& Best, L.B. (1985). The effect of disturbance on mourning dove nesting success. Auk, 102, 774- 780 . 